\title{
Uptake mechanisms for ascorbate and dehydroascorbate in lymphoblasts from diabetic nephropathy and hypertensive patients
}

\author{
L. L.Ng, F. C. Ngkeekwong, P. A. Quinn, J. E. Davies \\ Department of Medicine and Therapeutics, Leicester Royal Infirmary, Leicester, UK
}

\begin{abstract}
Summary In diabetic nephropathy and hypertension, a major cause of mortality is from cardiovascular disease. Since low levels of antioxidants such as vitamin $\mathrm{C}$ have been associated with such complications, we have examined the uptake mechanisms for ascorbic acid (AA) and dehydroascorbic acid (DHA) in lymphoblasts from normal control subjects $(\mathrm{CON})$, normoalbuminuric insulin-dependent diabetic (IDDM) patients (DCON), patients with IDDM and nephropathy (DN) and hypertensive patients (HT) using mass assays of uptake and measuring AA using high-performance liquid chromatography. Precautions were taken to prevent oxidation of AA and to take into account the instability of DHA in buffers. DHA uptake was the major mechanism in all four groups of subjects, and the $\mathrm{V}_{\max }$ (maximal uptake rate) was significantly lower in the DN cells $(24.7 \pm 1.0 \mathrm{nmol}$ [ $95 \%$ confidence intervals CI 22.5, 26.3] $10^{6}$ cells $\left.^{-1} \mathrm{~h}^{-1}\right)$ compared to CON and DCON cells $(33.9 \pm 2.1[95 \% \mathrm{CI}$ $29.4,38.4]$ and $37.0 \pm 2.2$ [95\% CI 32.2, 41.8] nmol
\end{abstract}

$10^{6}$ cells $^{-1} \mathrm{~h}^{-1}$, respectively, $p<0.001$ for both). DHA $\mathrm{V}_{\max }$ was also lower in the HT group $(23.2 \pm 1.1$ [95\% CI 20.7, 25.7] nmol $10^{6}$ cells $^{-1} \mathrm{~h}^{-1}$ ) compared to the CON group $(p<0.001)$. There were no significant differences in the $\mathrm{K}_{\mathrm{m}}$ or passive membrane permeability for DHA or the AA uptake. DHA uptake showed a negative correlation to systolic blood pressure $\left(r_{\mathrm{s}}=-0.49, p<0.001\right)$. These findings suggest that impaired DHA uptake may be one component of the phenotype expressed by DN cells that may persist in culture. Impaired DHA uptake in vivo, especially in the presence of hyperglycaemia, leads to impaired regeneration of $\mathrm{AA}$ and depletion of anti-oxidant defences, exposing such individuals to increased risk of cardiovascular disease. [Diabetologia (1998) 41: 435-442]

Keywords Ascorbic acid, dehydroascorbic acid, lymphoblasts, diabetic nephropathy, hypertension.
Insulin-dependent diabetes mellitus (IDDM), especially the nephropathy subset [1], and hypertension are linked to a high prevalence of cardiovascular morbidity and mortality. The pathology of this cardiovas-

Received: 10 July 1997 and in final revised form: 24 November 1997

Corresponding author: Dr. L. L. Ng, Department of Medicine and Therapeutics, Clinical Sciences Building, Leicester Royal Infirmary, Leicester LE2 7LX, UK

Abbreviations: AA, Ascorbic acid; ANOVA, analysis of variance; $\mathrm{CON}$, normal control; DCON, normoalbuminuric diabetic patients; DN, patients with diabetic nephropathy; DHA, dehydroascorbic acid; HBSS, HEPES buffered saline solution; HT, hypertension; PBS, phosphate buffered saline cular disease is predominantly due to large vessel disease or atherosclerosis, although microangiopathy is also important. The initiation and progression of atherosclerosis depends on many factors, although one recent attractive hypothesis implicates the damaging effects of reactive oxidative free radicals [2]. Natural defences against these reactive radicals include several free radical scavenging systems such as $\alpha$-tocopherol and ascorbic acid (AA) [3]. The water soluble AA may facilitate the recycling of the lipophilic $\alpha$-tocopherol and reduce lipid peroxidation and production of oxidised low density lipoproteins [3]. Indeed, low AA status in the population has been associated with higher rates of cardiovascular diseases such as stroke and coronary heart disease [4-6]. In addition, 
body stores of vitamin $\mathrm{C}$ have been negatively correlated with systolic and diastolic blood pressure [4]. Previous studies of AA status in diabetic patients by using plasma or leukocyte levels have indicated that there is a relative deficiency of AA in hyperglycaemic subjects, with lower levels in those with microangiopathy [7-10]. The uptake of dehydroascorbic acid (DHA) was reduced in diabetic subjects [8] due to reduction in $\mathrm{V}_{\max }$. However, in these studies of cellular vitamin $\mathrm{C}$ uptake, it was unclear whether environmental factors such as hyperglycaemia or genetic factors could have contributed to the altered vitamin C uptake, since uptake was measured in cells freshly isolated from diabetic subjects. Uptake was also investigated with radioisotopes [8] which assumed that the label remained unaltered and only unidirectional flux was measured, rather than the direct measurement of AA or DHA mass which would determine the net uptake of these vitamin $\mathrm{C}$ forms. Furthermore, uptake assays were not performed with precautions to prevent AA oxidation to DHA [8] and did not correct for the instability of DHA in physiological buffers [11]. Uptake of vitamin $\mathrm{C}$ has, to our knowledge, not been studied in hypertensive subjects.

Recent advances in the measurement of AA and DHA with sensitive and specific techniques such as high-performance liquid chromatography (HPLC) $[12,13]$ enabled mass assays of AA and DHA uptake $[11,14-19]$. Both high and low affinity uptake systems for AA and DHA have been described in a variety of cells. An examination of vitamin $\mathrm{C}$ uptake in human lymphoblasts using HPLC to measure AA and DHA uptake has defined two distinct high affinity uptake systems [11] in these cells. The maximal uptake rates for DHA exceeded that of AA and while glucose competitively inhibited DHA uptake, AA uptake was driven by the extra- to intracellular $\mathrm{Na}^{+}$gradient [11]. The finding that high glucose levels reduced DHA uptake would explain previous observations of a reduced $\mathrm{V}_{\max }$ for uptake of radiolabelled DHA in leukocytes from diabetic subjects [8].

In order to determine whether DHA uptake was further impaired in the group of IDDM patients with nephropathy who are especially prone to cardiovascular disease independently of in vivo factors, we have measured the uptake of AA and DHA using mass assays in cultured human lymphoblasts derived from three groups of subjects, namely non-diabetic controls $(\mathrm{CON})$, normoalbuminuric IDDM patients (DCON) and IDDM patients with nephropathy (DN). These cells have previously been utilized to elucidate the intermediate phenotype of increased $\mathrm{Na}^{+} / \mathrm{H}^{+}$exchanger activity in $\mathrm{DN}$ and hypertension $(\mathrm{HT})$, in isolation from the environmental influences present in vivo such as glycaemic control and lipid levels [20]. We have also compared vitamin C transport between the control group and an HT group because the latter also have a higher prevalence of car- diovascular disease. In addition, the DN patients may also have a predisposition to hypertension due to their associated membrane transport abnormalities of $\mathrm{Na}^{+} / \mathrm{H}^{+}$exchanger [20] and $\mathrm{Li}^{+} / \mathrm{Na}^{+}$countertransport [21, 22].

\section{Subjects and methods}

Patient selection. The study group of 12 diabetic normoalbuminuric and 15 diabetic nephropathy patients were recruited from the Joslin Clinic, Boston, Mass., USA and were all of Caucasoid origin. The IDDM patients had developed the disease before the age of 21. Nephropathy was defined as albumin excretion rate (AER) on one timed urine collection above $300 \mu \mathrm{g} / \mathrm{min}$ and normoalbuminuria as an AER less than $20 \mu \mathrm{g} /$ min despite 15-21 years of diabetes. Patients with nephropathy were also albustix positive. The 10 non-diabetic normoalbuminuric hypertensive patients and 15 normotensive control subjects were recruited from among non-related Caucasoid individuals in the Boston area and secondary hypertension was excluded by clinical and biochemical evaluations. Hypertension was defined as a diastolic pressure greater than $90 \mathrm{~mm}$ $\mathrm{Hg}$ or systolic pressure greater than $140 \mathrm{~mm} \mathrm{Hg}$. Four hypertensive patients were on anti-hypertensive medication. None of the normotensive control patients had a family history of hypertension. Informed consent was obtained from all patients and the protocol was approved by the local ethics committee. Lymphocytes from these subjects were immortalized by Epstein-Barr virus transformation and these lymphoblast lines were obtained from Dr. A.S. Krolewski, Genetics Core, Diabetes and Endocrinology Research Centre, Joslin Diabetes Centre, Boston, Mass., USA.

Materials and cell culture. AA, non-esterified fatty acid free bovine serum albumin, glutamine, penicillin, streptomycin, bromine solution and RPMI 1640 medium were from Sigma Chemicals Ltd., Poole, Dorset, UK. Fetal calf serum was from Advanced Protein Products, Birmingham, UK. RPMI 1640 growth medium contained $2 \mathrm{mmol} / \mathrm{l}$ glutamine, $15 \%$ fetal calf serum, $5 \mathrm{mmol} / 1$ glucose, $10^{5} \mathrm{IU} / \mathrm{l}$ penicillin, $100 \mathrm{mg} / \mathrm{l}$ streptomycin and buffered with $24 \mathrm{mmol} / \mathrm{l} \mathrm{NaHCO}_{3}(\mathrm{pH} 7.4$ in $95 \%$ air, $5 \% \mathrm{CO}_{2}$ ). HPLC grade acetonitrile and water was from $\mathrm{Fi}$ sons, Loughborough, U.K. Human lymphoblasts from the CON, DCON, DN and HT groups of subjects were maintained in RPMI 1640 growth medium at a density between 0.25 and $1 \times 10^{6}$ cell $/ \mathrm{ml}$ by regularly changing the medium every 2 days, as previously described [20]. Fresh stocks of cells were recovered from liquid nitrogen storage every 2 months to ensure consistency in uptake studies.

Mass transport assays for $A A$ and $D H A$. These uptake assays were described in detail previously [11]. Briefly, approximately $5 \times 10^{6}$ cells were used for each assay. Cells were washed twice in HEPES buffered saline solution (HBSS) composed of (in mmol/l) $140 \mathrm{NaCl}, 5 \mathrm{KCl}, 1.8 \mathrm{CaCl}_{2}, 0.8 \mathrm{MgSO}_{4}, 5$ glucose, 10 HEPES, $1 \mathrm{NaH}_{2} \mathrm{PO}_{4}$ with $\mathrm{pH}$ adjusted to 7.4. DHA was prepared from $\mathrm{AA}$ a few minutes before use by bromine oxidation of AA $[11,15,16]$. The exact amounts of freshly prepared AA or DHA were then pipetted into the tubes containing prewarmed known numbers of cells and incubated for $1 \mathrm{~h}$ (for AA uptake) or 20 min (for DHA uptake). AA uptake was determined using a substrate concentration of $1 \mathrm{mmol} / \mathrm{l} \mathrm{AA}$ in the presence and absence of extracellular $\mathrm{Na}^{+}$(substituting $\mathrm{Na}^{+}$with $\mathrm{N}$-methyl-D-glucamine) since in $\mathrm{Na}^{+}$free media, 
Table 1. Clinical characteristics of the study groups

\begin{tabular}{|c|c|c|c|c|}
\hline & $\mathrm{DN}$ & DCON & $\mathrm{CON}$ & HT \\
\hline Number (male) & $15(9)$ & $12(4)$ & $15(5)$ & $10(5)$ \\
\hline Age (years) & $36[23-40]$ & 36 [27-43] & 35 [20-79] & $46[34-69]^{\mathrm{g}}$ \\
\hline Body mass index $\left(\mathrm{kg} \mathrm{m}^{-2}\right)$ & $25.0 \pm 1.8$ & $22.9 \pm 1.1$ & $26.4 \pm 1.6$ & $34.9 \pm 2.0^{\mathrm{d}}$ \\
\hline Duration of diabetes (years) & $23.3 \pm 0.8$ & $23.7 \pm 0.4$ & & \\
\hline Family history of hypertension & 9 & 4 & 0 & 8 \\
\hline Insulin dose (IU/day) & $49 \pm 4$ & $51 \pm 5$ & & \\
\hline $\mathrm{HbA}_{1}$ & $12.0 \pm 0.4^{\mathrm{b}}$ & $10.5 \pm 0.4$ & & \\
\hline Albumin excretion rate $(\mu \mathrm{g} / \mathrm{min})$ & $1573^{\mathrm{f}}[320-9000]$ & $6.5[3-13]$ & & \\
\hline Creatinine $(\mu \mathrm{mol} / \mathrm{l})$ & $178 \pm 45^{\mathrm{a}}$ & $68 \pm 3$ & $80 \pm 6$ & $88 \pm 10$ \\
\hline Systolic blood pressure (mm Hg) & $148 \pm 5^{\mathrm{c}, \mathrm{e}}$ & $110 \pm 3$ & $111 \pm 3$ & $143 \pm 4^{\mathrm{e}}$ \\
\hline Diastolic blood pressure $(\mathrm{mm} \mathrm{Hg})$ & $92 \pm 4^{\mathrm{c}, \mathrm{e}}$ & $74 \pm 9$ & $74 \pm 2$ & $92 \pm 1^{\mathrm{e}}$ \\
\hline Retinopathy: Minimal & 0 & 4 & & \\
\hline Background & 5 & 6 & & \\
\hline Proliferative & 10 & 2 & & \\
\hline
\end{tabular}

Data are mean \pm SEM or median [range]

Student's $t$-test

${ }^{\mathrm{a}} p<0.05 ;{ }^{\mathrm{b}} p<0.01 ;{ }^{\mathrm{c}} p<0.005$ compared to DCON.

${ }^{\mathrm{d}} p<0.01 ;{ }^{\mathrm{e}} p<0.001$ compared to $\mathrm{CON}$.

more than $90 \%$ of the AA uptake was abolished [11]. The $\mathrm{Na}^{+}$ dependent AA uptake at $1 \mathrm{mmol} / \mathrm{l} \mathrm{AA}$ also approximates to the $\mathrm{V}_{\max }$ of the uptake mechanism [11].

DHA is very unstable in $\mathrm{HBSS}$ at $37^{\circ} \mathrm{C}$ and we had previously determined that the rate of degradation $\left(\mathrm{k}\right.$, in $\left.\min ^{-1}\right)$ was a complex function of the DHA concentration ([DHA] expressed in $\mu \mathrm{mol} / \mathrm{l})$ as illustrated [11], and could be estimated as follows [11]:

$\mathrm{k}=2.94 \times 10^{-8}[\mathrm{DHA}]^{2}-1.42 \times 10^{-4}[\mathrm{DHA}]+0.192$

This enabled the mean concentration of DHA to be estimated over the 20 min period of incubation during DHA uptake studies. All uptake studies were repeated on at least 2 to 3 different occasions and the results averaged for presentation. Betweenassay coefficients of variation for DHA and AA uptake were under $2 \%$.

Uptake in both cases was terminated by plunging tubes into ice, washing cells three times in phosphate buffered saline before lysing cells in $0.5 \mathrm{ml}$ of $20 \mathrm{~g} / \mathrm{l}$ metaphosphoric acid / $0.54 \mathrm{mmol} / 1$ EDTA $[11,23]$. The supernatants were stored at $-70{ }^{\circ} \mathrm{C}$ and were analysed within 1 week of the uptake studies.

Measurement of $A A$ and $D H A$ using HPLC. Cell extracts were subjected to isocratic HPLC to measure their AA content, on a Whatman Partisil 10 SAX anion exchange column, with acetonitrile / $50 \mathrm{mmol} / 1 \mathrm{KH}_{2} \mathrm{PO}_{4}$ (3/1 by volume) as the mobile phase as previously described $[11,12]$. DHA was measured by reducing it to AA using dithiothreitol (10 mmol/l) after neutralisation. In all cell lines, initial cellular AA content was not measurable in the absence of added AA or DHA in the extracellular medium. Moreover, in cell extracts when DHA uptake was being measured, the major form of vitamin $\mathrm{C}$ within the cells was AA (98\%) even without the use of dithiothreitol indicating that DHA was reduced by cellular enzymes such as the NADPH dependent DHA reductase $[11,16]$. We measured the total cellular AA content following dithiothreitol reduction of any remaining cytoplasmic DHA since this was the total amount of DHA that traversed the cell membrane during uptake measurements.
Mann Whitney test

${ }^{\mathrm{f}} p<0.002$ compared to DCON. ${ }^{\mathrm{g}} p<0.05$ compared to CON.

Uptake of DHA mass was best described by the sum of a saturable high affinity mechanism obeying Michaelis-Menten kinetics and a passive diffusional component:

Total uptake $=\frac{\mathrm{V}_{\max }[\mathrm{DHA}]}{[\mathrm{DHA}]+\mathrm{K}_{\mathrm{m}}}+\mathrm{k}[\mathrm{DHA}]$

where $K_{m}$ is the affinity of the uptake for DHA and $k$ is the passive diffusional rate constant for DHA. These parameters were calculated using P-fit (Biosoft Corporation, Cambridge, $\mathrm{UK})$.

Statistical analysis. Data were analysed using an Oxstat statistics package (Microsoft Corporation, Reading, Berks, UK) or a Statsgraphics package. Means and SEM are reported, and comparisons were by Student's $t$-test and analysis of variance (ANOVA). Non-normally distributed data are reported as medians [ranges] and compared using the Mann Whitney test. Two tailed $p$ values less than 0.05 were considered significant. Spearman correlation coefficients were also computed. Multiple regression analysis was performed with forward selection of predictor variables, with the $F$ ratio above which variables were entered set at 4 .

\section{Results}

Table 1 shows the patient characteristics in this study. DN and DCON patients were matched for age, duration of diabetes, and body mass index. The systolic and diastolic blood pressures in the $\mathrm{DN}$ patients were higher than both DCON and CON subjects. DN patients had worse glycaemic control than DCON patients (Table 1) and they had a higher prevalence of proliferative retinopathy. The HT patients had a higher body mass index and were older than the CON group.

The uptake of AA in all lymphoblasts was lower than that of DHA (Table 2). AA uptake measured 
Table 2. AA and DHA uptake rates in the study groups. Results are means \pm SEM. AA uptake rates were measured with $1 \mathrm{mmol} / \mathrm{l} \mathrm{AA}$ in media

\begin{tabular}{lllll}
\hline & DN & DCON & CON & HT \\
\hline $\begin{array}{l}\text { AA uptake } \\
\left(\text { pmol h}^{-1} 10^{6}\right.\end{array}$ & $197 \pm 47$ & $351 \pm 95$ & $344 \pm 98$ & $362 \pm 85$ \\
cells $\left.^{-1}\right)$ & & & & \\
$\begin{array}{l}\text { DHA uptake } \\
\mathrm{V}_{\max }\end{array}$ & $24.7 \pm 1.0^{\mathrm{a}}$ & $37.0 \pm 2.2$ & $33.9 \pm 2.1$ & $23.2 \pm 1.1^{\mathrm{a}}$ \\
$\left(\mathrm{nmol} \mathrm{h}^{-1} 10^{6}\right.$ & {$[22.5,26.3]$} & {$[32.2,41.8]$} & {$[29.4,38.4]$} & {$[22.5,26.3]$} \\
cells $\left.^{-1}\right)$ & $149 \pm 15$ & $148 \pm 18$ & $177 \pm 23$ & $161 \pm 22$ \\
$\mathrm{~K}_{\mathrm{m}}$ & & & & \\
$(\mu \mathrm{mol} / \mathrm{l})$ & $10.9 \pm 1.1$ & $9.1 \pm 1.9$ & $11.8 \pm 1.7$ & $6.8 \pm 1.0$ \\
$\mathrm{k}$ & & & & \\
$\begin{array}{l}\text { (passive diffusion } \\
\text { constant) } \\
\left(\mathrm{pmol} \mathrm{h}^{-1} 10^{6}\right.\end{array}$ & & & & \\
cells $\left.{ }^{-1} \mu \mathrm{mol} / \mathrm{l}^{-1}\right)$ & & & & \\
\hline
\end{tabular}

Data are mean \pm SEM. [95\% confidence intervals]

Student's $t$-test

${ }^{\mathrm{a}} p<0.001$ compared to DCON and CON.

at $1 \mathrm{mmol} / \mathrm{l}$ of the substrate in the absence and presence of $\mathrm{Na}^{+}$enabled the $\mathrm{Na}^{+}$driven component of uptake to be measured (being over $90 \%$ of the total uptake). Although AA uptake rates in DN cells was lower than DCON and CON cells, this did not reach statistical significance. Furthermore, the uptake of AA in the HT cells was not significantly impaired compared to CON cells. Measurements of $\mathrm{K}_{\mathrm{m}}$ were not possible in all the lines due to the low rates of uptake at lower AA concentrations around the $\mathrm{K}_{\mathrm{m}}$ in some of the lines studied [11].

The uptake of DHA was the major mechanism responsible for the intracellular accumulation of vitamin $\mathrm{C}$ in all the cell lines studied (Table 2). All the lines possessed saturable DHA uptake that satisfied Michaelis-Menten kinetics. Over a wide range of concentrations of substrate, DHA uptake was lower in the DN group compared to the DCON group (Fig.1). The uptake of DHA was also lower in the HT group compared to the CON group (Fig. 2). An examination of the kinetics of the DHA uptake mechanism revealed that the $\mathrm{K}_{\mathrm{m}}$ was similar between all four groups of subjects (Table 2). ANOVA for the values for the passive diffusional component of DHA uptake (representing the passive membrane permeability to DHA) revealed no significant differences between groups. Although the mean value in the HT group was numerically lower than in the other groups, this was not statistically significant on a Mann Whitney test.

However, the $\mathrm{V}_{\max }$ of the DHA uptake mechanism showed substantial variation, and ANOVA of these values using the Oxstat statistics package indicated significant differences between groups $(p<0.005)$. DHA uptake in both the CON and DCON exhibited

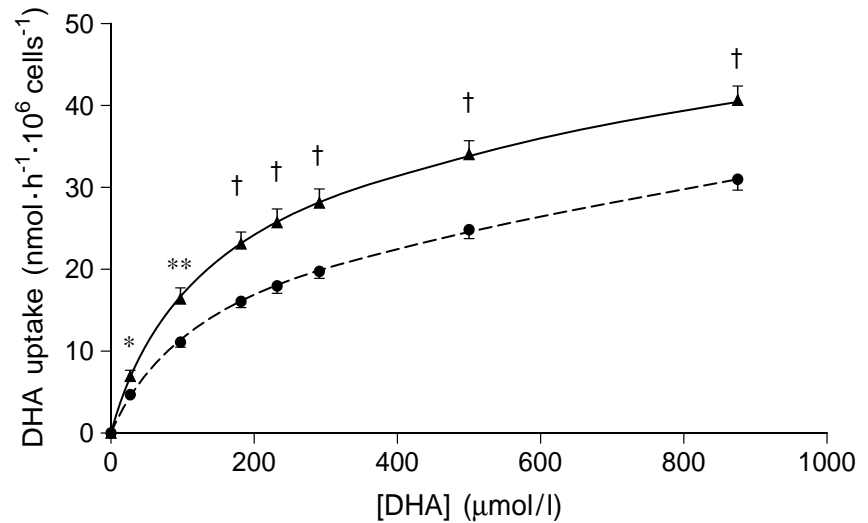

Fig. 1. Mass uptake of DHA in lymphoblasts from DN $(\bullet)$ and (A) DCON subjects at different concentrations of DHA. Means \pm SEM for each DHA concentration are plotted for $15 \mathrm{DN}$ and 12 DCON cell lines. $* p<0.01$; $* * p<0.005$; $+p<0.001)$

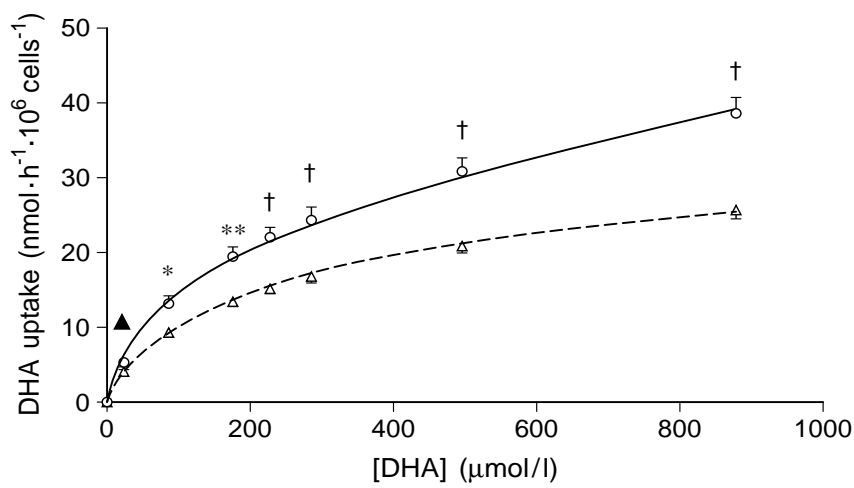

Fig. 2. Mass uptake of DHA in lymphoblasts from CON $(O)$ and HT $(\triangle)$ subjects at different concentrations of DHA Means \pm SEM for each DHA concentration are plotted for $15 \mathrm{CON}$ and $10 \mathrm{HT}$ cell lines. ( $\boldsymbol{\Delta} p<0.05 ; * p<0.01$; $\left.* * p<0.005 ;{ }^{+} p<0.001\right)$

a two-fold range in contrast to the smaller ranges of values in the HT and DN groups (Fig. 3). Post hoc comparisons of DHA uptake in CON and DCON cell lines indicated that uptake rates were not significantly higher in the DCON cell lines. However, DHA uptake rates in the DN cell lines were significantly lower than both the CON $(p<0.001)$ and DCON $(p<0.001)$ cell lines (Fig. 3). When cell lines from patients with minimal background retinopathy were compared with those with proliferative retinopathy in the diabetic groups, those with proliferative retinopathy had significantly lower DHA $\mathrm{V}_{\max }$ values than those with background retinopathy $(26.3 \pm 1.7$ [95\% confidence intervals CI 22.6, 30.0] compared to $34.3 \pm 2.4[95 \%$ CI $29.4,39.2] \mathrm{nmol} 10^{6} \mathrm{cells}^{-1} \mathrm{~h}^{-1}$, $p<0.01$ ), reflecting the high prevalence of proliferative retinopathy in the $\mathrm{DN}$ group.

Since there were more males in the DN group, we calculated the DHA $V_{\text {max }}$ rates for males and females for the whole group. There was no significant differ- 


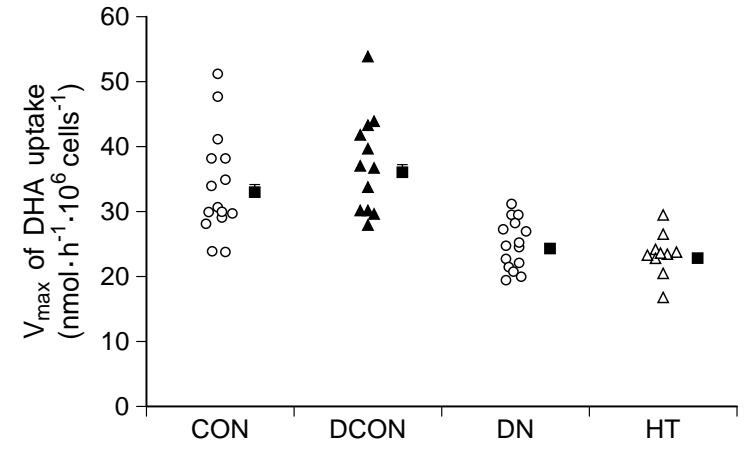

Fig.3. The $\mathrm{V}_{\max }$ values for DHA uptake in the four groups of subjects. Kinetic parameters were determined and averaged over 2-3 separate occasions. Means and SEM for each group are also plotted

ence between these values (male $32.2 \pm 2.2$ compared to female $30.9 \pm 1.5 \mathrm{nmol} 10^{6}$ cells $\left.^{-1} \mathrm{~h}^{-1}\right)$. Thus, the lower $\mathrm{V}_{\max }$ values in DN cells could not be due to a male preponderance. There was no significant correlation between the DHA $\mathrm{V}_{\max }$ and glycosylated haemoglobin, age, body mass index, insulin dose or duration of diabetes. Thus, it was unlikely that the chronic hyperglycaemia that cells were exposed to in vivo in the diabetic subjects could have influenced the lower measured $\mathrm{V}_{\max }$ values in DN cells. However, a significant negative correlation between DHA $\mathrm{V}_{\max }$ and systolic blood pressure was present in the diabetic group in the absence of antihypertensive therapy $\left(r_{\mathrm{s}}=-0.49, p<0.001\right)$, although the correlation with diastolic blood pressure was not significant $\left(r_{\mathrm{s}}=-0.22\right)$.

Multiple regression analysis of the data in the DCON and DN groups was then performed using a stepwise forward variable selection procedure, with the DHA $\mathrm{V}_{\max }$ as the outcome variable and age, body mass index, creatinine, gender, log albumin excretion rate, glycosylated haemoglobin, blood pressure and presence or absence of nephropathy as predictor variables. Two predictor variables were selected with significant contributions to the variance of DHA $V_{\max }$ and these were presence or absence of

Table 3. Multiple regression analysis of data in DCON and DN groups and the CON and HT groups using the DHA $\mathrm{V}_{\max }$ as the outcome variable and stepwise forward variable selection nephropathy and systolic blood pressure (Table 3 ). These two factors accounted for $63 \%$ of the total variance $(p<0.0001)$.

The lower DHA uptake rates in the HT group (Fig. 2) were attributed to lower $\mathrm{V}_{\max }$ values when the kinetic parameters were examined (Table 2). The $\mathrm{V}_{\max }$ values were clustered within a narrow range (Fig. 3), with a distribution similar to the DHA uptake in the DN group. The average DHA $\mathrm{V}_{\max }$ uptake rate in the HT group was significantly lower than in the CON group $(p<0.001$, Fig. 3$)$. This finding was unlikely to be influenced by the anti-hypertensive medication in four of the patients since the cells were cultured in vitro for at least 2 months before the studies and the effect of the drugs should have waned. There was no significant correlation between DHA $\mathrm{V}_{\max }$ and age or body mass index.

Multiple regression analysis of the data in the CON and HT groups was performed using a stepwise forward variable selection procedure with the DHA $\mathrm{V}_{\max }$ as the outcome variable and age, body mass index, creatinine, gender, blood pressure and presence or absence of hypertension as predictor variables. Two predictor variables were selected with significant contributions to the variance of DHA $\mathrm{V}_{\max }$ and these were presence or absence of hypertension (entered as a dummy or indicator variable) and age (Table 3 ). These two factors accounted for $59 \%$ of the total variance $(p<0.0001)$. The correlation coefficient for age in the model was however positive.

\section{Discussion}

The transport mechanisms for AA and DHA that we have described in lymphoblasts have also been reported in a variety of other cell types, including neutrophils and fibroblasts [14-18]. In addition, the leucocyte pool in vivo accounts for a substantial proportion of the total body AA content. Although diabetes has been associated with a depleted AA status [7-10], the mechanism for this has not been

Predictor variables with significant independent associations with the DHA $V_{\max }$ are reported, with values for the slope coefficients $\beta( \pm$ SEM $)$ and \% of the total variance of the model attributable to the predictor variables

\begin{tabular}{|c|c|c|c|}
\hline & $\beta( \pm$ SEM $)$ & $P$ value & Variance attributed to factor \\
\hline $\begin{array}{l}\text { DCON and DN } \\
\text { Presence or absence of nephropathy } \\
(1=\text { present, } 0=\text { absent })\end{array}$ & $-20.65( \pm 3.67)$ & 0.0001 & $53 \%$ \\
\hline $\begin{array}{l}\text { Systolic blood pressure }(\mathrm{mm} \mathrm{Hg}) \\
\text { CON and HT }\end{array}$ & $0.18( \pm 0.07)$ & 0.02 & $10 \%$ \\
\hline $\begin{array}{l}\text { Presence or absence of hypertension } \\
(1=\text { present, } 0=\text { absent }) \\
\text { Age (years) }\end{array}$ & $\begin{array}{l}-13.56( \pm 2.43) \\
0.24( \pm 0.08)\end{array}$ & 0.0001 & $41 \%$ \\
\hline
\end{tabular}


fully explored. A previous study examined the uptake of radiolabelled DHA in leukocytes in a small number of diabetic patients and a lower $\mathrm{V}_{\max }$ for DHA uptake was suggested [8]. However, this impairment of uptake may have resulted from the higher ambient glucose levels to which cells were subjected, since glucose competitively inhibits DHA uptake [11] with a $K_{i}$ in the physiological range $(2.2 \mathrm{mmol} / \mathrm{l})$. Moreover, chronic exposure of cells to high glucose levels could lead to a reduction in $\mathrm{V}_{\max }$ of DHA uptake, an effect that was not due to the increased osmolarity [11]. Furthermore, although it is well established that DHA is very unstable in aqueous solutions, kinetic parameters may be over-estimated if no adjustments are made for DHA hydrolysis [11]. DHA has to be freshly prepared to ensure that concentrations are exactly as expected. For these reasons, it was not possible to conclude that DHA uptake was impaired in this previous study due to an intrinsic defect in the cells. Our present study is the first to investigate DHA uptake with these precautions taken to ensure true kinetic parameters are determined. Furthermore, culture of the cell lines in vitro in media of standardized glucose composition ensured that such environmental factors were controlled for.

The present studies indicated that DHA uptake rates in DN cells may be impaired when compared to CON and DCON cells. This impairment of DHA uptake in DN may become significant when it is most needed during oxidative stress in the extracellular milieu. The impaired uptake would reduce the regeneration of AA from DHA within the cells (Fig. 4), and this would lead to irreversible loss of DHA through its hydrolysis in aqueous solution. In vivo, the presence of hyperglycaemia would further exacerbate this loss since we had previously demonstrated that DHA and glucose compete for the same uptake mechanism [11]. In addition, chronic hyperglycaemia may also downregulate the DHA uptake mechanism leading to further reduction in the $\mathrm{V}_{\max }$ in vivo [11]. The hyperglycaemic milieu may therefore be expected to lower DHA recycling most profoundly in the DN group of patients, with intermediate levels in the DCON group.

The present study also demonstrates for the first time that DHA uptake may also be impaired in HT and depletion of the antioxidant AA due to defective DHA cycling may be one factor for the high prevalence of cardiovascular disease in this group. Transport abnormalities common to DN and HT have previously been identified [20-22], such as enhanced cellular $\mathrm{Na}^{+} / \mathrm{H}^{+}$exchanger activity and erythrocyte $\mathrm{Li}^{+} / \mathrm{Na}^{+}$countertransport. The impairment of DHA uptake in both pathological conditions is another example of the alterations in membrane transport shared by these two conditions. Multiple regression analysis of our data also revealed that the major contributors to the variance in the $\mathrm{DHA} \mathrm{V}_{\max }$ were presence of hypertension or diabetic nephropathy with smaller contributions from age and systolic blood pressure. Gender, body mass index, plasma creatinine and glycosylated haemoglobin were not significant predictor variables.

There is strong evidence that the family of facilitative glucose transporters mediates the uptake of DHA [18] and GLUT1 may be the major putative transporter involved as it is the predominant transporter expressed in lymphoblasts [24]. The present finding of lowered $V_{\max }$ of DHA uptake in DN and HT groups with no difference in the $\mathrm{K}_{\mathrm{m}}$ may indicate a reduced plasma membrane density or turnover number of GLUT1 in these cells, but further molecular characterisation of the DHA uptake mechanism is necessary.

Previous studies have established an important role for AA in a variety of physiological processes that may be relevant to cardiovascular or renal disease, in addition to a contribution to antioxidant defences. Platelet function relies on adequate AA levels [25]. An important role for AA in the synthesis of collagen and proteoglycans [26-29] may suggest that a relative deficiency could lead to alterations in aryl sulfatase B activity and reduced sulfation of glycosaminoglycans, and hence altered basement membrane charge, permeability and function. Alterations of basement membrane charge and permeability have been implicated in the pathogenesis of diabetic complications involving the cardiovascular and renal systems [30]. Furthermore, AA plays an important role in the improvement of endothelial function in patients with both diabetes and cardiovascular disease $[31,32]$ and the inhibition of the rate-limiting step of cholesterol synthesis, 3-hydroxy-3-methyl glutaryl coenzyme A reductase [33]. An action of AA on improving insulin action on whole body glucose disposal especially via non-oxidative pathways, may be relevant to the maintenance of glucose homeostasis in vivo [34].

In the present studies, AA uptake was always performed in the presence of dithiothreitol, so that this was the only species of vitamin $\mathrm{C}$ present. This confirmed that the uptake of AA was indeed the minor component for total vitamin $\mathrm{C}$ uptake in these cells, compared to the large transport capacity for DHA. In previous studies, we have demonstrated that reducing agents per se have no significant effect on AA uptake [11]. It is uncertain whether the role of this AA transport mechanism is to export the AA regenerated from the DHA that is taken up by the DHA mechanism (Fig. 4). Thus, at physiological plasma concentrations of AA ranging from 30 to $100 \mu \mathrm{mol} / 1[4,9,10]$ and DHA ranging from 10 to $30 \mu \mathrm{mol} / 1$ [9], the AA uptake would be operating at $50-90 \%$ full capacity but DHA uptake would only be at about $10 \%$ full capacity. The absolute rates 


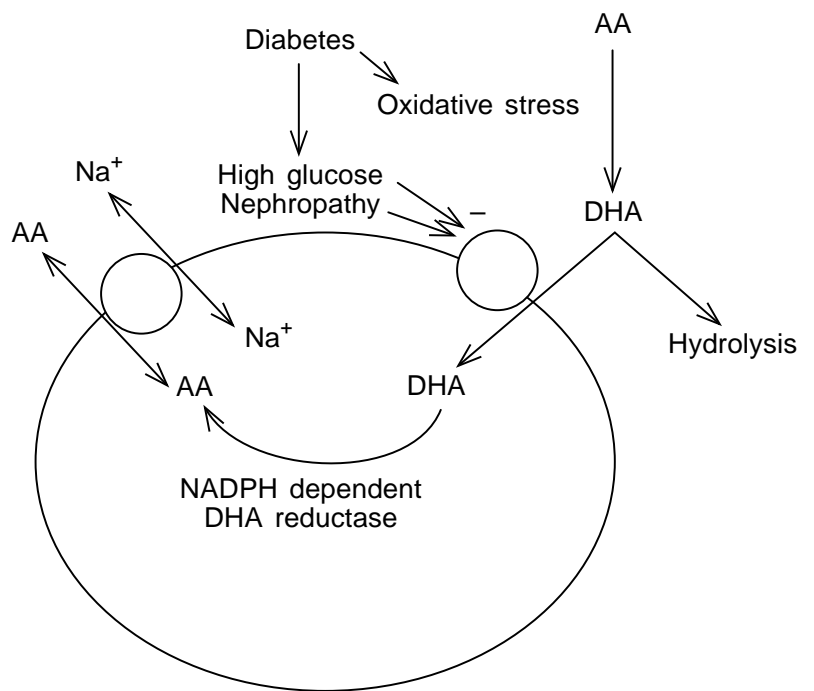

Fig.4. Scheme illustrating the major mechanism for vitamin $\mathrm{C}$ uptake and recycling involving DHA. DHA is generated from AA in extracellular fluid due to oxidative stress, and in order to be regenerated by the intracellular enzyme DHA reductase, it has to be taken up by cells by a saturable transport mechanism. The DHA is then reduced to AA by cytoplasmic NAD$\mathrm{PH}$ dependent DHA reductase so that the major intracellular form of vitamin $\mathrm{C}$ is AA. This could then be reutilized as antioxidant defences within and outside the cells. Impairment of DHA uptake in DN cells especially in the presence of poor glycaemic control (which competitively inhibits DHA uptake or further downregulates the $\mathrm{V}_{\max }$ of the uptake mechanism) leads to hydrolysis and irrecoverable loss of DHA, eventually resulting in depletion of AA stores

of uptake of DHA exceed that of AA by $10-15$ fold even at these plasma concentrations of substrate, and being on the linear part of the uptake curve would respond to increases in plasma DHA by marked increases in uptake rates. These kinetic parameters would be especially useful when oxidative stress leads to oxidation of AA in the extracellular fluid, generating DHA that would enhance its cellular uptake, and this is then rapidly reduced back to AA within the cells through DHA reductase [16]. Diabetes has been associated with a greater degree of oxidative stress in vivo $[9,35]$. This mechanism ensures that AA is recovered and recycled rather than the antioxidant pool being depleted gradually by irreversible DHA hydrolysis. Thus, the roles of the AA uptake mechanism may be to maintain cellular anti-oxidant defences, whereas the DHA uptake mechanism may act predominantly to regenerate DHA formed from extracellular oxidative stress. According to this model, hyperglycaemia, nephropathy status in diabetic patients and hypertension will impair the recycling of vitamin $\mathrm{C}$ by inhibiting DHA uptake. In some pathological conditions, these three factors can have an additive effect so that cellular stores of vitamin $\mathrm{C}$ are decreased further.
In conclusion, mass assays of AA and DHA uptake in cell lines have defined two distinct uptake mechanisms for these vitamin $\mathrm{C}$ forms. Although AA uptake is similar in all four groups of subjects, the uptake of DHA is reduced in DN and HT cell lines. In association with poor glycaemic control in vivo, DHA uptake could be further reduced. This impairs the ability to recycle oxidised AA and may result in the depletion of antioxidant defences. The links of this phenotype with the increased prevalence of cardiovascular disease in diabetic nephropathy, hypertension and their pathophysiological mechanisms remains to be explored.

Acknowledgements. F. C. Ngkeekwong was supported by the Smith and Nephew Foundation, the Wolfson Trust and the British Pharmacological Society. We also thank the Wellcome Trust for their support. We are very grateful to Dr. A.S. Krolewski, Joslin Diabetes Centre, Boston, USA for supplying us with the cell lines for these studies.

\section{References}

1. Krolewski AS, Warram JH, Rand LI, Kahn CR (1987) Epidemiologic approach to the etiology of type 1 diabetes mellitus and its complications. $\mathrm{N}$ Engl J Med 317: $1390-1398$

2. Wirztum JL (1994) The oxidation hypothesis of atherosclerosis. Lancet 344: 793-795

3. Levine M (1986) New concepts in the biology and biochemistry of ascorbic acid. N Engl J Med 314: 892-902

4. Trout DL (1991) Vitamin C and cardiovascular risk factors. Am J Clin Nutr 53: 322S-325S

5. Gey KF, Moser UK, Jordan P, Stahelin HB, Eichholzer M, Ludin E (1993) Increased risk of cardiovascular disease at suboptimal plasma concentrations of essential antioxidants: an epidemiological update with special attention to carotene and vitamin C. Am J Clin Nutr 57 [Suppl]: 787S-797S

6. Nyyssonen K, Parviainen MT, Salonen R, Tuomilehto J, Salonen JT (1997) Vitamin C deficiency and risk of myocardial infarction: prospective population study of men from eastern Finland. Br J Med 314: 634-638

7. Som S, Basu S, Mukherjee D et al. (1981) Ascorbic acid metabolism in diabetes mellitus. Metabolism 30: 572-577

8. Stankova L, Riddle M, Larned J et al. (1984) Plasma ascorbate concentrations and blood cell dehydroascorbate transport in patients with diabetes mellitus. Metabolism 33: 347-353

9. Sinclair AJ, Girling AJ, Gray L, Le Guen C, Lunec J, Barnett AH (1991) Disturbed handling of ascorbic acid in diabetic patients with and without microangiopathy during high dose ascorbate supplementation. Diabetologia 34: 171-175

10. Cunningham JJ, Ellis SL, McVeigh KL, Levine RE, CallesEscandon J (1991) Reduced mononuclear leukocyte ascorbic acid content in adults with insulin-dependent diabetes mellitus consuming adequate dietary Vitamin C. Metabolism 40: 146-149

11. Ngkeekwong FC, Ng LL (1997). Two distinct uptake mechanisms for ascorbate and dehydroascorbate in human lymphoblasts and their interaction with glucose. Biochem $\mathrm{J}$ 324: $225-230$ 
12. Doner LW, Hicks KB (1986) High-performance liquid chromatographic separation of ascorbic acid, erythorbic acid, dehydroascorbic acid, dehydroerythorbic acid, diketogulonic acid, and diketogluconic acid. Methods Enzymol 122: 3-10

13. Washko PW, Welch RW, Dhariwal KR, Wang Y, Levine M (1992) Ascorbic acid and dehydroascorbic acid analyses in biological samples. Analyt Biochem 204: 1-14

14. Washko P, Levine M (1992) Inhibition of ascorbic acid transport in human neutrophils by glucose. J Biol Chem 267: 23568-23574

15. Washko PW, Wang Y, Levine M (1993) Ascorbic acid recycling in human neutrophils. J Biol Chem 268: 15531-15535

16. Welch RW, Wang Y, Crossman A, Park JB, Kirk KL, Levine $M$ (1995) Accumulation of vitamin C (ascorbate) and its oxidized metabolite dehydroascorbic acid occurs by separate mechanisms. J Biol Chem 270: 12584-12592

17. Vera JC, Rivas CI, Zhang RH, Farber CM, Golde DW (1994) Human HL-60 myeloid leukemia cells transport dehydroascorbic acid via the glucose transporters and accumulate reduced ascorbic acid. Blood 84: 1628-1634

18. Vera JC, Rivas CI, Fischbarg J, Golde DW (1993) Mammalian facilitative hexose transporters mediate the transport of dehydroascorbic acid. Nature 364: 79-82

19. Vera JC, Rivas CI, Velasques FV, Zhang RH, Concha II, Golde DW (1995) Resolution of the facilitated transport of dehydroascorbic acid from its intracellular accumulation as ascorbic acid. J Biol Chem 270: 23706-23712

20. Ng LL, Davies JE, Siczkowski M et al. (1994) Abnormal $\mathrm{Na}^{+} / \mathrm{H}^{+}$antiporter phenotype and turnover of immortalized lymphoblasts from type 1 diabetic patients with nephropathy. J Clin Invest 93: 2750-2757

21. Krolewski AS, Canessa M, Warram JH et al. (1988) Predisposition to hypertension and susceptibility to renal disease in insulin-dependent diabetes mellitus. $\mathrm{N}$ Engl $\mathrm{J}$ Med 318:140-145

22. Mangili R, Bending JJ, Scott G, Li LK, Gupta A, Viberti GC (1988) Increased sodium-lithium countertransport activity in red cells of patients with insulin-dependent diabetes and nephropathy. N Engl J Med 318:146-150

23. Mitton KP, Trevithick JR (1994) High-performance liquid chromatography-electrochemical detection of antioxidants in vertebrate lens: glutathione, tocopherol and ascorbate. Methods Enzymol 233: 523-539
24. Pessin JE, Bell GI (1992) Mammalian facilitative glucose transporter family: structure and molecular regulation. Annu Rev Physiol 54: 911-930

25. Sarji KE, Kleinfelder J, Brewington P, Gonzalez J, Hempling H, Colwell JA (1979) Decreased platelet vitamin C in diabetes mellitus: possible role in hyperaggregation. Thromb Res 15: 639-650

26. Klein DJ, Oegema TR Jr, Brown DM (1989) Release of glomerular heparan ${ }^{35} \mathrm{SO}_{4}$ proteoglycan by heparin from glomeruli of streptozocin-induced diabetic rats. Diabetes 38: 130-139

27. Cohen MP, Klepser H, Wu V-Y (1988) Undersulfation of glomerular basement membrane heparan sulfate in experimental diabetes and lack of correction with aldose reductase inhibition. Diabetes 37: 1185-1188

28. Fisher E, McLennan SV, Tada H, Heffernan S, Yue DK, Turtle JR (1991) Interaction of ascorbic acid and glucose on production of collagen and proteoglycan by fibroblasts. Diabetes 40: 371-376

29. Selvidge LA, Verlangieri AJ (1991) Inhibition of arylsulfatase B by ascorbic acid. Res Commun Chem Pathol Pharmacol 73: 253-256

30. Deckert T, Kofoed-Enevoldsen A, Norgaard K et al. (1992) Microalbuminuria. Implications for micro- and macrovascular disease. Diabetes Care 15: 1181-1191

31. Ting HH, Timimi FK, Boles KS, Creager SJ, Ganz P, Creager MA (1996) Vitamin C improves endothelium-dependent vasodilation in patients with non-insulin-dependent diabetes mellitus. J Clin Invest 97: 22-28

32. Levine GN, Frei B, Koulouris SN, Gerhard MD, Keaney Jr JF, Vita JA (1996) Ascorbic acid reverses endothelial vasomotor dysfunction in patients with coronary artery disease. Circulation 93: 1107-1113

33. Harwood HJ, Greene YJ, Stacpoole PW (1986) Inhibition of human leukocyte 3-hydroxy-3-methyl glutaryl coenzyme A reductase activity by ascorbic acid. J Biol Chem 261: 7127-7135

34. Paolisso G, D'Amore A, Balbi V et al. (1994) Plasma vitamin $\mathrm{C}$ affects glucose homeostasis in healthy subjects and in non-insulin-dependent diabetics. Am $\mathrm{J}$ Physiol 267:E261-E268

35. Baynes JW (1991) Role of oxidative stress in the development of complications in diabetes mellitus. Diabetes 40: 405-412 